\title{
Economic Order Quantity Model for Growing Items with Incremental Quantity Discounts, Capacitated Storage Facility, and Limited Budget
}

\author{
Yosi Agustina Hidayat ${ }^{1}$, Veterina Nosadila Riaventin ${ }^{1}$, Okky Jayadi2 $^{*}$
}

\begin{abstract}
The development of the inventory model started when Harris introduced the classic inventory model. It was firstly published by Wilson using the optimization method. He derived a mathematical equation model to obtain economic order quantities. Later, this model is known as the classic Economic Order Quantity (EOQ) or Wilson Model. The classic inventory EOQ model has some limitations. The model assumed that order items do not have physical changes during a planning period. This assumption becomes the weakness of the classical EOQ inventory model. Many items have material changes during a planning period, such as amelioration, deterioration, and growth. This research proposed a new mathematical model. The model relaxes three implicit assumptions of the classical EOQ: (1) the ordered items do not grow; (2) unlimited capacity; and (3) unlimited budget. A solution procedure to solve the model was developed and illustrated with a numerical example. A numerical example was performed to compare the result between the reference model and the new model. The number of ordered items per cycle time increased by $7 \%$, and cycle time increased by $28 \%$. It increased because the proposed model tends to choose large purchased quantities to get a cheap price. It caused the number of ordered items per cycle time to be larger and the cycle time to be smaller than the reference model. This research also provided sensitivity analysis. It showed the response of decision variables to some changes in input parameters.
\end{abstract}

Keywords: Economic order quantity, growing item, incremental quantity discount, capacitated storage facility, limited budget.

\section{Introduction}

Mishra [1] explained that the development of inventory modelling began in the second decade of the 19th century when Harris introduced the first inventory model. Later, Wilson developed it by deriving formulas of a mathematical model to obtain economic order quantities. The model is known as the classic EOQ. The application of the Harris model has a limitation. His assumptions may not be realistic. Harris assumed that order items do not have physical changes during a planning period. This assumption has been the weakness of Harris' model, because there are items that have material changes during a planning period, such as amelioration, deterioration, and growth. Research about this topic is still new. There are not many researchers who work on this topic. In this problem, many researchers proposed the models by relaxing one or two assumptions. This research focused on growing items, such as palm oil fruit, poultry, and fishery. In real conditions, when a farmer buys newborn animal (recently born, i.e. one-day-old), he will take care of them by feeding them until they grow according to their expectations.

${ }^{1}$ Faculty of Industrial Technology, Industrial Engineering Department, Institut Teknologi Bandung, Jl. Ganeca 10, Bandung, 40132 Indonesia. Email: yosi@mail.ti.itb.ac.id, veterina@itb.ac.id,okky.jayadi@students.itb.ac.id

* Corresponding author
Growth on these items is defined as growing items.

Rezaei [2] was the first researcher who worked on growing items and proposed a model with growing items characteristic. Zhang et al. [3] proposed model with growing items and carbon tax characteristics. Nobil et al. [4] proposed model with growing items shortages characteristics. Sebatjane and Adetunji [5] proposed model with growing items and imperfect quality. Sebatjane and Adetunji [6] proposed model with growing items and limited storage capacity. Later on, Sebatjane and Adetunji [7] proposed model with growing items and incremental quantity discounts characteristics. This research proposes new mathematical modelling by relaxing three implicit assumptions of the classic EOQ, i.e. (1) the ordered items do not grow; (2) unlimited capacity; and (3) unlimited budget. Model development in this research combines two models developed in Sebatjane and Adetunji's [6,7] and consider the limited budget situation. A comparison of the proposed model and related researches is provided in Table 1 . Table 1 shows some comparations of the previous researches in terms of inventory system characteristics, such as conventional items, growing items, incremental quantity discounts, limited budget, and limited storage capacity. 
Table 1. State of the art in this research

\begin{tabular}{|c|c|c|c|c|c|c|c|}
\hline \multirow[b]{2}{*}{ Year } & \multirow[b]{2}{*}{ Researchers } & \multicolumn{5}{|c|}{ Major of inventory system characteristics } & \multirow[b]{2}{*}{$\begin{array}{l}\text { Additional } \\
\text { characteristics }\end{array}$} \\
\hline & & $\begin{array}{l}\text { Conventional } \\
\text { items }\end{array}$ & $\begin{array}{l}\text { Growing } \\
\text { items }\end{array}$ & $\begin{array}{c}\text { Incremental } \\
\text { quantity } \\
\text { discounts }\end{array}$ & $\begin{array}{l}\text { Limited } \\
\text { budget }\end{array}$ & $\begin{array}{l}\text { Limited } \\
\text { storage } \\
\text { capacity }\end{array}$ & \\
\hline 2011 & Limansyah and Lesmono [8] & $\checkmark$ & & $\checkmark$ & & & $\begin{array}{l}\text { Multi-item, } \\
\text { expiration date }\end{array}$ \\
\hline 2014 & Ghasmy Yaghin [9] & $\checkmark$ & & $\checkmark$ & & & Multi-objective \\
\hline 2014 & Rezaei [2] & & $\checkmark$ & & & & \\
\hline 2014 & Holobom and Segerstedt [10] & $\checkmark$ & & & & & Lot scheduling \\
\hline 2014 & Zhang et al. [11] & $\checkmark$ & & & & & Advance payment \\
\hline 2015 & Taleizadeh et al. [12] & $\checkmark$ & & $\checkmark$ & & & $\begin{array}{l}\text { Partial } \\
\text { Backordering }\end{array}$ \\
\hline 2016 & Nafish et al. [13] & $\checkmark$ & & $\checkmark$ & & & $\begin{array}{l}\text { Expiration date } \\
\text { Backordering }\end{array}$ \\
\hline 2016 & Zhang et al. [3] & & $\checkmark$ & & & & Carbon tax \\
\hline 2017 & Bohner and Minner [14] & $\checkmark$ & & $\checkmark$ & & & Supplier selection \\
\hline 2017 & $\begin{array}{l}\text { Thamjidzad and Mirmohammadi } \\
\text { [15] }\end{array}$ & $\checkmark$ & & $\checkmark$ & & & \\
\hline 2018 & $\begin{array}{l}\text { Moammadiyojdan and } \\
\text { Geunes [16] }\end{array}$ & $\checkmark$ & & $\checkmark$ & & & $\begin{array}{l}\text { Probabilistic } \\
\text { demand }\end{array}$ \\
\hline 2018 & Nobil et al. [4] & & $\checkmark$ & & & & Shortages \\
\hline 2019 & $\begin{array}{l}\text { Khalilpourazari and Pasandideh } \\
\text { [17] }\end{array}$ & & $\checkmark$ & & & & $\begin{array}{l}\text { Multi-item, multi- } \\
\text { constrained }\end{array}$ \\
\hline 2019 & Malekitabar et al. [18] & & $\checkmark$ & & & & \\
\hline 2019 & Sebatjane and Adetunji [5] & & $\checkmark$ & & & & Imperfect quality \\
\hline 2019 & Sebatjane and Adetunji [6] & & $\checkmark$ & & & $\checkmark$ & \\
\hline 2019 & Sebatjane and Adetunji [7] & & $\checkmark$ & $\checkmark$ & & & \\
\hline 2020 & Gharaei and Almehdwe [19] & & $\checkmark$ & & & & \\
\hline 2020 & Oluleye [0] & $\checkmark$ & & $\checkmark$ & & & \\
\hline 2020 & Raj and Priskillal [21] & $\checkmark$ & & $\checkmark$ & & & \\
\hline 2020 & Rasay and Golmohammadi [22] & $\checkmark$ & & $\checkmark$ & & & \\
\hline 2020 & Wangsa and Wee [23] & $\checkmark$ & & $\checkmark$ & & & Freight cost \\
\hline 2020 & This Research & & $\checkmark$ & $\checkmark$ & $\checkmark$ & $\checkmark$ & \\
\hline
\end{tabular}

\section{Methods}

The research methodology is divided into seven steps, consisting literature review; preliminary studies; mathematical model development; algorithm development; numerical example; analysis; and conclusion and future research. The first step is a literature review. This step is conducted to compile state of the art (SOTA) from previous investigations related to the case to be resolved. The second step is preliminary studies. The preliminary studies were divided into two stages, namely problem identification and problem analysis. The preliminary studies aim to find out the initial conditions of the real system that exists. Thus, it can identify the existing problem and analyse the existing problem. This preliminary study will be the basis for carrying further research steps. The third step is the mathematical model development. This step is divided into three stages, namely the formulation of the problem, the development of the mathematical model, and verification of the mathematical model. The fourth step is algorithm development. This step is divided into two stages, namely, algorithm development and verification of the algorithm development. The fifth step is a numerical example. This step is carried out to test the developed model that can be used which begin with parameterizing the model. Inputs to the numerical example are a mathematical model and algorithm. The output on the numerical example is the solution to the problem. The sixth step is analysis. This step is divided into two stages, namely comparative analysis and sensitivity analysis. The seventh step is the conclusion and future research. The conclusion is drawn based on all the results of this research that has been done by answering the formulation of an existing problem. Future research provides input to further research that can be developed.

\section{Problem Definition}

The system in this paper is related to an inventory system. In this system, a company orders a certain number of items which are capable of growing during 
a planning period, for example, palm oil fruit, poultry and fishery. The supplier of the new-born items offers incremental quantity discounts over a fixed price. The discounted price is only applied to the incremental quantity. Sebatjane and Adetunji [6] explained the behaviour of an inventory system for growing items in Figure 1. The company have to feed the item to grow before the item reach the targeted weight of consumption. Every replenishment cycle can be divided into two periods, namely the growth and the consumption. This research works on the case of a linear growth function. The company incurs the purchasing cost, setup cost, and food procurement cost. Holding cost and food procurement cost are separated since the storage capacity of the owner is limited. Therefore, the company is able to rent a facility from another party. At the beginning of a growing cycle, the company needs to determine the optimal number of live newborn item to order, and the frequencies of placing orders which minimizes the total cost. The total cost is defined as the summation of purchasing cost, setup cost, holding cost and food procurement cost, but not over the limited budget. The proposed model is to minimize total cost, with decision variables of (1) number of live new-born items, and (2) cycle time.

\section{Assumptions}

The proposed mathematical model assumes: (1) A single type of item. (2) The item can be growing. (3) Linear growth function. (4) Feeding costs are proportional to the weight gained by the item. (5) Holding costs are incurred for the duration of the consumption period. (6) The supplier offers incremental quantity discounts. (7) Item arrives at both facilities at the same time. (8) The company has a limited capacity. (8) The company has a limited budget. (9) The holding cost at the rented facility is higher than the privateowned facility. (10) Items in the private-owned facility are sold after those in the rented facility reaches a sold-out condition. (11) The inventory phenomenon is deterministic.

\section{Notations}

Table 2. Notations of the Mathematical Model

\begin{tabular}{|c|c|c|}
\hline Symbol & Unit & Description \\
\hline$Y_{i j}$ & item & $\begin{array}{l}\text { Number of ordered items } \\
\text { per cycle time for iteration } i \\
\text { and price } j\end{array}$ \\
\hline$T_{i}$ & year & Cycle time for iteration $i$ \\
\hline$m$ & item & $\begin{array}{l}\text { Capacity of the private- } \\
\text { owned facility }\end{array}$ \\
\hline$w_{0}$ & $\frac{\mathrm{kg}}{\text { item }}$ & $\begin{array}{l}\text { Approximated weight of } \\
\text { each new-born item }\end{array}$ \\
\hline$w_{1}$ & $\frac{\mathrm{kg}}{\text { item }}$ & $\begin{array}{l}\text { Approximated weight of } \\
\text { each grown item at the } \\
\text { consumption time }\end{array}$ \\
\hline
\end{tabular}

\begin{tabular}{|c|c|c|}
\hline Symbol & Unit & Description \\
\hline$b$ & $\frac{\frac{k g}{\text { item }}}{\text { year }}$ & Growth rate of item \\
\hline$p_{j}$ & 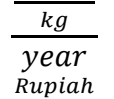 & Purchasing cost at $j$ \\
\hline$h_{o}$ & 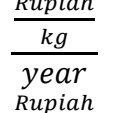 & $\begin{array}{l}\text { Holding cost in the private- } \\
\text { owned facility at } o\end{array}$ \\
\hline$h_{r}$ & $\begin{array}{l}\frac{\mathrm{kg}}{\text { year }} \\
\text { Rupiah }\end{array}$ & $\begin{array}{l}\text { Holding cost in the rented } \\
\text { facility at } r\end{array}$ \\
\hline$K$ & $\frac{\mathrm{kg}}{\text { year }}$ & Setup cost \\
\hline$D_{1}$ & $\frac{k g}{\text { year }}$ & Demand \\
\hline$D_{2}$ & $\frac{k g}{y e a r}$ & $\begin{array}{l}\text { Demand that can be } \\
\text { fulfilled immediately after } \\
\text { limited budget }\end{array}$ \\
\hline$c$ & $\frac{\frac{\text { Rupiah }}{\mathrm{kg}}}{\text { year }}$ & Feeding cost \\
\hline$t$ & year & Growing period \\
\hline$t_{r}$ & year & $\begin{array}{l}\text { Consumption period in the } \\
\text { rented facility at } r\end{array}$ \\
\hline$t_{o}$ & year & $\begin{array}{l}\text { Consumption period in the } \\
\text { owned facility at } o\end{array}$ \\
\hline$y_{j}$ & item & $\begin{array}{l}\text { Lower bound for the order } \\
\text { quantity for price } j\end{array}$ \\
\hline$t_{s}$ & $\begin{array}{c}\text { year } \\
\text { Rupiah }\end{array}$ & Setup time at $s$ \\
\hline$x$ & $\frac{\text { year }}{\text { yecun }}$ & Limited budget \\
\hline$\eta_{i}$ & $\%$ & $\begin{array}{l}\text { Service level for each } i \\
\text { iteration }\end{array}$ \\
\hline
\end{tabular}

\section{Mathematical Model}

Growth function $\left(w_{1}\right)$ is obtained from the approximated weight of each new-born item $\left(w_{0}\right)$ plus multiplication of growth rate $(b)$ by a growing period $(t)$ as shown in Equation (1).

$w_{1}=w_{0}+b t$

Equation (2) shows the situation when Equation (1) considers all the ordered items as follows

$Y_{i j} w_{1}=Y_{i j} w_{0}+Y_{i j} b t$

Growing period can be deduced from (1) as follows,

$t=\frac{w_{1}-w_{0}}{b}$

Figure 1 describes the behaviour of the inventory system over time. The food procurement cost and holding cost in the private-owned and in the rented facility can be formulated by calculating the area of a decent area. This research uses weight to measure capacity by referring to Rezaei [2]. In this research, setup time is a fixed parameter, so it is not affected by the amount of weight of the inventory level. Thus, setup time only becomes a model constraint. 


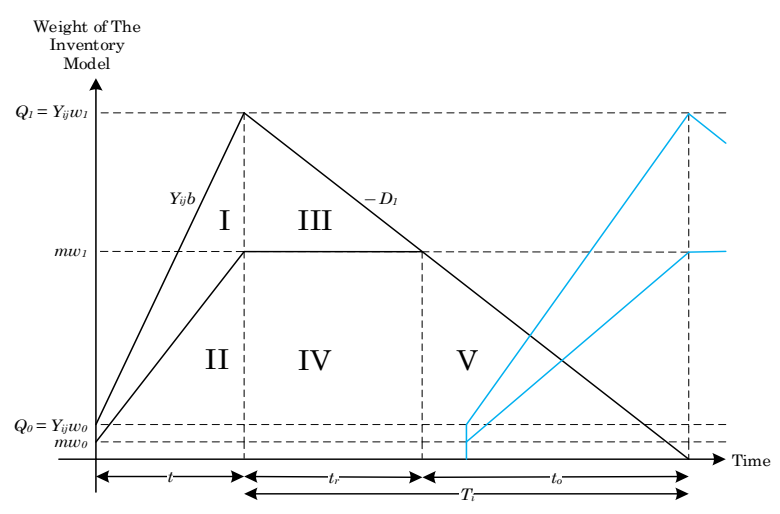

Figure 1. Inventory system behaviour for growing items with the owned facility, rented facility and linear growth function [6]

\section{Discount Cost Structure}

Purchasing cost per weight unit at the $j$ break point is symbolized by $p_{j}$. where $Y_{i j}$ is symbolized as number of ordered items per cycle time is in the range of $y_{j}$ to $y_{j+1}$.

\section{The Consumption Period in the Rented Facility}

Figure 1 explained that $t_{r}$ as shown in Equation (4) is obtained from the weight of the inventory in the rented facility $\left(Y_{i j}-m\right) w_{1}$ divided by annual demand $\left(D_{1}\right)$.

$t_{r}=\frac{\left(Y_{i j}-m\right) w_{1}}{D_{1}}$

\section{The Consumption Period in The Owned Facility}

Figure 1 explained that $t_{o}$ as shown in Equation (5) is obtained from the weight of the inventory in the owned facility $\left(m w_{1}\right)$ divided by annual demand $\left(D_{1}\right)$.

$t_{o}=\frac{m w_{1}}{D_{1}}$

\section{Cycle Time}

Figure 1 explained that $t_{o}$ as shown in Equation (6) is obtained from the sum of the consumption periods in both facilities

$T_{i}=\frac{Y_{i j} w_{1}}{D_{1}}$

\section{Purchasing Cost per Cycle}

Purchasing cost per cycle is equal to the sum of purchasing cost on the previous price offered by the supplier plus the existing one.

$P C=R_{j}+p_{j} w_{0}\left(Y_{i j}-y_{j}\right)$

where,

$R_{j}=$
$\begin{cases}p_{1}\left(y_{2}-y_{1}\right) w_{0}+\cdots+p_{j-1}\left(y_{j}-y_{j-1}\right) w_{0}, & j \geq 2 \\ 0, & j=1\end{cases}$

\section{Setup Cost per Cycle}

Setup cost per cycle as shown in Equation (9) is incurred for setting-up feeding facilities at the beginning of each cycle.

$S C=K$

Food Procurement Cost in the Rented Facility per Cycle

The area under part one, i.e., the subtracted area of the triangle I to triangle II, represents the food procurement cost in the rented facility per cycle

$F C_{r}=c\left[\frac{\left(w_{1}-w_{0}\right)\left[\left(Y_{i j}-m\right) w_{1}-\left(Y_{i j}-m\right) w_{0}\right]}{2 b}\right]$

Food Procurement Cost in the Owned Facility per Cycle

Area under triangle II represents the food procurement cost in the owned facility per cycle.

$F C_{o}=c\left[\frac{\left(w_{1}-w_{0}\right)\left(m w_{1}-m w_{0}\right)}{2 b}\right]$

\section{Food Procurement Cost per Cycle}

The food procurement cost per cycle is equal to the sum of the food procurement cost in both facilities per cycle.

$$
\begin{aligned}
F C= & c\left[\frac{\left(w_{1}-w_{0}\right)\left[\left(Y_{i j}-m\right) w_{1}-\left(Y_{i j}-m\right) w_{0}\right]}{2 b}\right]+ \\
& c\left[\frac{\left(w_{1}-w_{0}\right)\left(m w_{1}-m w_{0}\right)}{2 b}\right]
\end{aligned}
$$

\section{Holding Cost in the Rented Facility}

The area under triangle III represents the holding cost in the rented facility

$H C_{r}=h_{r}\left[\frac{\left(Y_{i j}-m\right)^{2} w_{1}^{2}}{2 D_{1}}\right]$

\section{Holding Cost in the Owned Facility}

Holding cost in the owned facility is obtained by calculating the area of rectangle IV added with the area of triangle $\mathrm{V}$.

$H C_{o}=h_{o}\left[\frac{m\left(Y_{i j}-m\right) w_{1}^{2}}{D_{1}}+\frac{m^{2} w_{1}^{2}}{2 D_{1}}\right]$

\section{Holding Cost per Cycle}

Holding cost per cycle is equal to the sum of holding cost in both facilities per cycle. 


$$
H C=h_{r}\left[\frac{\left(Y_{i j}-m\right)^{2} w_{1}^{2}}{2 D_{1}}\right]+h_{o}\left[\frac{m\left(Y_{i j}-m\right) w_{1}^{2}}{D_{1}}+\frac{m^{2} w_{1}^{2}}{2 D_{1}}\right]
$$

\section{Total Cost per Cycle}

Total cost per cycle is the summation of the purchasing cost per cycle, setup cost per cycle, food procurement cost per cycle, and holding cost per cycle.

$$
\begin{aligned}
C= & R_{j}+p_{j} w_{0}\left(Y_{i j}-y_{j}\right)+K+ \\
& {\left[\frac{\left(w_{1}-w_{0}\right)\left[\left(Y_{i j}-m\right) w_{1}-\left(Y_{i j}-m\right) w_{0}\right]}{2 b}\right]+} \\
& C\left[\frac{\left(w_{1}-w_{0}\right)\left[\left(Y_{i j}-m\right) w_{1}-\left(Y_{i j}-m\right) w_{0}\right]}{2 b}\right]+ \\
& C\left[\frac{\left(w_{1}-w_{0}\right)\left(m w_{1}-m w_{0}\right)}{2 b}\right]+h_{r}\left[\frac{\left(Y_{i j}-m\right)^{2} w_{1}{ }^{2}}{2 D_{1}}\right]+ \\
h_{o} & {\left[\frac{m\left(Y_{i j}-m\right)^{2} w_{1}{ }^{2}}{D_{1}}+\frac{m^{2} w_{1}{ }^{2}}{2 D_{1}}\right] }
\end{aligned}
$$

\section{Total Cost per Unit Time}

Total cost per unit time is equal to the total cost per cycle divided by unit time $(T)$.

$$
\begin{gathered}
T C U_{i}=D_{1}\left(\frac{R_{j}}{Y_{i j} w_{1}}+\frac{p_{j} w_{0}}{w_{1}}-\frac{p_{j} w_{0} y_{j}}{Y_{i j} w_{1}}\right)+\frac{K}{T}+ \\
C\left(\frac{D_{1}\left(w_{1}-w_{0}\right)^{2}}{2 b w_{1}}\right)+h_{r}\left(\frac{D_{1} T}{2}\right)+ \\
\left(h_{o}-h_{r}\right)\left(m w_{1}-\frac{m^{2} w_{1}^{2}}{2 D_{1} T}\right)
\end{gathered}
$$

\section{Demand for Limited Budget}

Demand for limited budget is equal to the purchasing cost per cycle divided by unit time $(T)$ and solve it for demand $\left(D_{1}\right)$.

$D_{2}=D_{1}-\frac{(P C U-x) Y_{i j} w_{1}}{p_{j} w_{0} y_{j}-Y_{i j} p_{j} w_{0}-R_{j}}$

Insufficient budget owned causes declining demand to meet all the consumer's needs. Thus, it will affect the company service level. Liu, et al. [24] proposed a service level model using the percentage of the immediate fulfilment of the requested number.

$\eta_{i}=\left(\frac{D_{2}}{D_{1}}\right) 100 \%$

\section{Constraint}

To ensure the consumption items are ready for sale on time, then, the growing period plus the setup time should be less than or equal to cycle time.

$t+t_{s} \leq T$

By substituting (3) into (20), we can get equation (21) as follows,

$T \geq\left(\frac{w_{1}-w_{0}}{b}+t_{s}=T_{\min }\right)$

\section{Solution}

\section{Determination of the Decisions Variables}

According to Bazarra et al. [25], the necessary condition to find the optimal cycle time is obtained by setting the first derivative of the objective function equally to zero. They are shown in (22) and (23).

$\frac{\partial T C U}{\partial T}=\frac{\left(h_{m}-h_{r}\right) m^{2} w_{1}^{2}}{2 D_{1} T^{2}}+\frac{D_{1} h_{r}}{2}-\frac{K}{T^{2}}=0$

$T_{i}=\sqrt{\frac{\frac{\left(h_{O}-h_{r}\right) m^{2} w_{1}^{2}}{D_{1}}+2 K}{D_{1} h_{r}}}$

Obtaining the solution of the decision variable $T$ in the (24) then we need to substitute (23) into (6) to get the optimal number of ordered items per cycle time. The result is shown in (24).

$Y_{i j}=\frac{D_{1} \sqrt{\frac{\frac{\left(h_{O}-h_{r}\right) m^{2} w_{1}^{2}}{D_{1}}+2 K}{D_{1} h_{r}}}}{w_{1}}$

\section{Proof of Convexity of The Objective Function}

According to Bazarra et al. [25], sufficient condition is obtained from the Hessian matrix. Consider a symmetric matrix $\boldsymbol{H}=\left[\begin{array}{ll}a & b \\ b & c\end{array}\right]$. Then $\boldsymbol{H}$ is positive semi definite if and only if $a \geq 0$ and $|\boldsymbol{H}|<0$. If $a \geq 0$ and $|\boldsymbol{H}| \geq 0$ then $\boldsymbol{H}$ positive definite. Based on theory explained by Bazarra et al. [25], our proposed model is sufficient if it meets the positive semi definite or positive definite requirements.

$\left[\begin{array}{ll}\frac{\partial^{2} T C U_{i}}{\partial T_{i}^{2}} & \frac{\partial^{2} T C U_{i}}{\partial T_{i} \partial Y_{i j}} \\ \frac{\partial^{2} T C U_{i}}{\partial Y_{i j} \partial T_{i}} & \frac{\partial^{2} T C U_{i}}{\partial Y_{i j}^{2}}\end{array}\right]$

$\left[\begin{array}{cc}\frac{-\left(h_{o}-h_{r}\right) m^{2} w_{1}^{2}}{D T_{i}{ }^{3}}+\frac{2 K}{T_{i}{ }^{3}} & 0 \\ 0 & \frac{-2\left(D_{1} p_{j} w_{0} y_{j}-D_{1} R_{j}\right)}{w_{1} Y_{i j}{ }^{3}}\end{array}\right]$

Since $\frac{-\left(h_{o}-h_{r}\right) m^{2} w_{1}^{2}}{D_{1} T_{i}{ }^{3}}+\frac{2 K}{T_{i}{ }^{3}} \geq 0$ and/or $|\boldsymbol{H}| \geq 0$, then the convexity of the objective function is fulfilled. Subsequently, our proposed model successfully reaches both sufficient and necessary conditions.

\section{Computational Algorithm}

We develop an algorithm for solving the proposed model. This algorithm consists of seven steps as follows:

Step 1. Calculate $T_{\text {min }}$ using (21).

Step 2. Check the feasibility. If $T_{\min }$ greater than or equal to zero, then it is feasible and proceeds to Step 3. Otherwise $T_{\min }$ less than 0 or $w_{0} \geq w_{1}$, then it is not feasible and proceed 
to Step 9. If $w_{0} \geq w_{1}$, it is not growing items problem, but problem occurs in perishable items that increase the value of decay or the decreased weight items, such as fruit and vegetables.

Step 3. Calculate $T_{i}$ using (23).

Step 4. Calculate $Y_{i j}$ 's feasibility. It is feasible if $y_{j} \leq$ $Y_{i j} \leq y_{j+1}$ then go to Step 5, otherwise it should be disregarded and only the feasible ones will be proceeded.

Step 5. Check the feasibility of each calculated $Y_{i j}$ with $T_{i}$. Each $Y_{i j}$ is feasible if $t+t_{s} \leq T_{i}$ then go to Step 6, otherwise it should be disregarded and only the feasible ones will be proceeded.

Step 6. Calculate $T C U_{i}$ using (17) for all the feasible $Y_{i j}$.

Step 7. Check the feasibility of each $T C U_{i}$. Each $T C U_{i}$ is feasible if $T C U_{i} \leq x$. Go to Step 8.

Step 8. Calculate service level using (19). If service level is $100 \%$ then go to Step 10, otherwise go to Step 9.

Step 9. Set $P C U=x$, find $D_{2}$ using (18) then go to Step 3.

Step 10. End.

\section{Results and Discussions}

\section{Numerical Example}

A numerical example utilizing the following parameters, mostly adapted from a study by Sebatjane and Adetunji [6,7]:

Demand $\left(D_{1}\right)$

Setup cost $(K)$

$: 100,000$

Holding cost in the owned facility $\left(h_{o}\right) \quad: 4$

Holding cost in the rented facility $\left(h_{r}\right) \quad: 6$

Capacity of the owned facility $(m) \quad: 100$

Approximated weight of each

new-born item $\left(w_{o}\right)$

Approximated weight of each grown

item at the consumption time $\left(w_{1}\right) \quad: 35$

Growth rate $(b) \quad: 73$

Setup time $\left(t_{s}\right) \quad: 0.01$

Feeding cost $(c) \quad: 0.025$

Limited budget $(x) \quad: 600,000$

The model solution is then calculated using the development of the proposed algorithm as follows:

Step 1. Calculate $T_{\min }$ using (21).

$$
T_{\min }=\frac{35-6.8}{73}+0.01=0.40 \text { year }
$$

Check the feasibility. If $T_{\min }$ greater than or equal to zero, then it is feasible and proceeds to Step 3. Otherwise $T_{\text {min }}$ less than 0 or $w_{0} \geq$ $w_{1}$, then it is not feasible and proceed to Step 9. If $w_{0} \geq w_{1}$, it is not growing items problem, but problem occurs in perishable items that increase the value of decay or the decreased weight items, such as fruit and vegetables.

$$
T_{\min } \geq 0
$$

Step 2.

Table 3. Purchased cost structure under incremental quantity discount

\begin{tabular}{ccc}
\hline Criteria & Quantity purchased & Price per weight unit \\
\hline 1 & $0-1,000$ & 25 \\
2 & $1,001-1,500$ & 20 \\
3 & $1,501-2,000$ & 15 \\
4 & $>2,000$ & 10 \\
\hline
\end{tabular}

Step 3. Calculate $T_{i}$ using Equation (23).

$T_{1}=\sqrt{\frac{\frac{(4-6) 100^{2} 35^{2}}{100,000}+(2)(75,000)}{(100,000)(6)}}=0.50$ year

$T_{2}=\sqrt{\frac{\frac{(4-6) 100^{2} 35^{2}}{68,600}+(2)(75,000)}{(68,600)(6)}}=0.60$ year

Step 4. Calculate $Y_{j}$ 's feasibility. They are feasible if $y_{j} \leq Y_{i j} \leq y_{j+1}$ then go to Step 5, otherwise it should be disregarded and only the feasible ones will be proceeded.

$R_{1}=0$

$R_{2}=25(1,001-0) 6.8=170,170$

$R_{3}=170,170+20(1,501-1,001) 6.8=238,170$

$R_{4}=238,170+15(2,001-1,501) 6.8=289,170$

$Y_{12}=\frac{D T}{w_{1}}=\frac{(100,000)(0.5)}{(35)}=1,428.57$

$$
\approx 1,429 \text { item }
$$

Only $Y_{12}$ is feasible, because 1,429 entered in the range from 1,001 to 1,500 .

$Y_{22}=\frac{D T}{w_{1}}=\frac{(68,600)(0.603)}{(35)}=1,181.88$ $\approx 1,182$ item

Only $Y_{22}$ is feasible, because 1,182 entered in the range from 1,001 to 1,500 .

Step 5. Check the feasibility of each calculated $Y_{i j}$ with $T_{i}$. Each $Y_{i j}$ is feasible if $t+t_{s} \leq T_{i}$ then go to Step 6, otherwise it should be disregarded and only the feasible ones will be proceeded.

$0.40 \leq 0.5$, then $Y_{12}$ is feasible.

$0.40 \leq 0.60$, then $Y_{22}$ is feasible.

Step 6. Calculate $T C U_{i}$ using Equation (17) for all the feasible $Y_{i j}$.

$T C U_{1}=100,000\left(\frac{170,170}{(1,429)(35)}+\frac{(20)(6.8)}{35}-\right.$

$\left.\frac{(20)(6.8)(1,001)}{1,429(35)}\right)+\frac{75,000}{0.50}+6\left(\frac{(100,000)(0.50)}{2}\right)+(4-$

6) $\left((100)(35)-\frac{100^{2} 35^{2}}{(2)(100,000)(0.50)}\right)+$

$2.5\left(\frac{100,000(35-6.80)^{2}}{(2)(73)(35)}\right)=788,770.38 \frac{\text { Rupiah }}{\text { year }}$ 


$$
\begin{aligned}
& T C U_{2}=68,600\left(\frac{170,170}{(1,182)(35)}+\frac{(20)(6.80)}{35}-\right. \\
& \left.\frac{(20)(6.80)(1,001)}{1,182(35)}\right)+\frac{75,000}{0.60}+6\left(\frac{(68,600)(0.60)}{2}\right)+(4- \\
& 6)\left((100)(35)-\frac{100^{2} 35^{2}}{(2)(68,600)(0.50)}\right)+ \\
& 2.5\left(\frac{68,600(35-6.80)^{2}}{(2)(73)(35)}\right)=591,456.61 \frac{\text { Rupiah }}{\text { year }}
\end{aligned}
$$

Step 7. Check the feasibility of each $T C U_{i}$. Each $T C U_{i}$ is feasible if $T C U_{i} \leq x$. Go to Step 8.

$788,770.38>600,000, T C U_{1}$ is over the budget. $591,456.61 \leq 600,000, T C U_{2}$ is lower than the budget.

Step 8. Calculate service level using Equation (19). If service level is $100 \%$ then go to Step 10, otherwise go to Step 9.

$\eta_{1}=\left(\frac{100,000}{100,000}\right) 100 \%=100 \%$

$\eta_{2}=\left(\frac{68,600}{100,000}\right) 100 \%=68.60 \%$

Service level after limited budget is lower than before, because the company does not have enough budgets to meet all consumer demands.

Step 9. Set $P C U=x$, find $D_{2}$ using Equation (18) then go to Step 3.

$D_{2}=D_{1}-\frac{(600,000-456,619.01)(1429)(35)}{(20)(6.80)(1001)-(1429)(20)(6.80)-170,170}=$
$68,599.43 \approx 68,600 \frac{\mathrm{kg}}{\text { year }}$

Step 10. End.

\section{Comparative Analysis}

Table 4 explains that the proposed model is different than Sebatjane and Adetunji's model [7]. The number of ordered items per cycle time is different because there is no limited budget and storage capacity in Sebatjane and Adetunji's model [7]. The proposed model tends to choose large purchased quantities to get a cheap price. It caused the number of ordered items per cycle time to be larger and the cycle time to be smaller than the reference model.

\section{Sensitivity Analysis}

In real situations, the certainty assumption is seldom satisfied precisely. Linear programming models usually are formulated to select some future course of actions. Therefore, the parameter values used would be based on a prediction of future conditions, which inevitably introduces some degrees of uncertainty. For this reason, it is usually important to conduct sensitivity analysis after a solution found that is optimal under the assumed parameter values Hillier and Lieberman [26].
Table 4. Comparison between Sebatjane and Adetunji's model [20] and this research

\begin{tabular}{ccccc}
\hline $\begin{array}{c}\text { Decision } \\
\text { variables, cost } \\
\text { components, } \\
Y_{i j}^{*} \text { and } \eta_{i}\end{array}$ & Units & $\begin{array}{c}\text { Sebatjane and } \\
\text { Adetunji [20] }\end{array}$ & $\begin{array}{c}\text { This } \\
\text { Research }\end{array}$ & $\begin{array}{c}\% \\
\text { Change }\end{array}$ \\
\hline$Y_{i j}^{*}$ & item & 1,335 & 1,429 & $7 \%$ \\
$T_{i}$ & year & 0.47 & 0.60 & $28 \%$ \\
$\eta_{i}$ & Unitless & $100 \%$ & $68.60 \%$ & $-31 \%$ \\
\hline
\end{tabular}

This research provides sensitivity analysis with six scenarios. In each scenario, one parameter is changed while the others are kept the same. The first scenario changes in feeding cost. The second scenario changes in setup costs. The third scenario changes in holding costs in the private-owned facility. The fourth scenario changes in holding costs in the rented facility. The fifth changes in the capacity of the private-owned facility. The sixth scenario changes in the approximated weight of each grown item. Table 5 shows the result of the sensitivity analysis from six scenarios.

Changes in feeding cost have no significant effect on the number of ordered items per cycle time and have a significant effect on the total cost per unit time. This condition means that if the feeding cost increases, it will make the total cost per unit time higher, whereas if the feeding cost decreases, it will make the total cost per unit time decreases. The conclusion is in line with the expected weight of the item before being consumed. If the item gets heavier, it will increase the feeding cost. Furthermore, changes in the setup cost have significant effects to the number of ordered items per cycle time and total cost per unit time. This condition means that if the feeding cost increases, it will make the number of ordered items per cycle time and total cost per unit time even higher. Whereas if the feeding cost decreases, it will make the number of ordered items per cycle time and total cost per unit cost it will reduce the frequency for reordering, but will increase the order size, which is closely related to holding costs. Changes in holding cost in the owned facility have a significant effect on the number of ordered items per cycle time and total cost per unit time. It means that increasing the value of the number of ordered items per cycle time will increase the value of total cost per unit time.

Furthermore, changes in holding cost in the rented facility have a significant effect on the number of ordered items per cycle time and total cost per unit time. Thus, changes the value of holding cost in the rented facility will increase total cost per unit time because the holding cost in the rented facility is more expensive than in the owned facility. Company management must reduce the number of items stored in the rented facility to reduce the value of total cost 
Table 5. Sensitivity analysis due to changes in some parameters

\begin{tabular}{|c|c|c|c|c|c|c|c|c|c|c|c|}
\hline \multirow[b]{2}{*}{ Scenario } & \multirow[b]{2}{*}{$\begin{array}{c}\% \\
\text { Change }\end{array}$} & \multicolumn{2}{|c|}{$Y_{i j}$} & \multicolumn{2}{|c|}{$T C U_{i}$} & \multirow[b]{2}{*}{ Scenario } & \multirow[b]{2}{*}{$\begin{array}{c}\% \\
\text { Change }\end{array}$} & \multicolumn{2}{|c|}{$Y_{i j}$} & \multicolumn{2}{|c|}{$T C U_{i}$} \\
\hline & & item & $\begin{array}{c}\% \\
\text { Change }\end{array}$ & $\frac{\text { Rupiah }}{\text { year }}$ & $\begin{array}{c}\% \\
\text { Change }\end{array}$ & & & item & $\begin{array}{c}\% \\
\text { Change }\end{array}$ & $\frac{\text { Rupiah }}{\text { year }}$ & $\begin{array}{c}\% \\
\text { Change }\end{array}$ \\
\hline \multirow{9}{*}{1} & -50 & 1,182 & 0 & $578,111.83$ & -2.26 & \multirow{9}{*}{4} & -50 & 1,675 & 41.71 & $539,463.70$ & -8.79 \\
\hline & -37.50 & 1,182 & 0 & $581,448.02$ & -1.69 & & -37.50 & 1,497 & 26.65 & $552,461.93$ & -6.59 \\
\hline & -25 & 1,182 & 0 & $584,784.22$ & -1.13 & & -25 & 1,366 & 15.57 & $565,460.15$ & -4.40 \\
\hline & -12.50 & 1,182 & 0 & $588,120.41$ & -0.56 & & -12.50 & 1,264 & 6.94 & $578,458.38$ & -2.20 \\
\hline & 0 & 1,182 & 0 & $591,456.61$ & 0 & & 0 & 1,182 & 0 & $591,456.61$ & 0 \\
\hline & 12.50 & 1,182 & 0 & $594,792.80$ & 0.56 & & 12.50 & 1,114 & -5.75 & $604,454.83$ & 2.20 \\
\hline & 25 & 1,182 & 0 & $598,129.00$ & 1.13 & & 25 & 1,057 & -10.58 & $617,453.06$ & 4.40 \\
\hline & 37.50 & 1,182 & 0 & $601,465.19$ & 1.69 & & 37.50 & 1,007 & -14.81 & $630,451.29$ & 6.59 \\
\hline & 50 & 1.182 & 0 & $604,801.39$ & 2.26 & & 50 & 964 & -18.44 & $643,449.51$ & 8.79 \\
\hline \multirow{9}{*}{2} & -50 & 835 & -29.36 & $529,267.55$ & -10.51 & \multirow{9}{*}{5} & -50 & 1,183 & 0.08 & $594,734.50$ & 0.55 \\
\hline & -37.50 & 934 & -20.98 & $544,814.82$ & -7.89 & & -37.50 & 1,183 & 0.08 & $593,901.15$ & 0.41 \\
\hline & -25 & 1,024 & -13.37 & $560,362.08$ & -5.26 & & -25 & 1,183 & 0.08 & $593,077.05$ & 0.27 \\
\hline & -12.50 & 1,106 & -6.43 & $575,909.34$ & -2.63 & & -12.50 & 1,183 & 0.08 & $592,262.20$ & 0.14 \\
\hline & 0 & 1,182 & 0.00 & $591,456.61$ & 0 & & 0 & 1,182 & 0 & $591,456.61$ & 0 \\
\hline & 12.50 & 1,254 & 6.09 & $607,003.87$ & 2.63 & & 12.50 & 1,182 & 0 & $590,660.27$ & -0.13 \\
\hline & 25 & 1,322 & 11.84 & $622,551.13$ & 5.26 & & 25 & 1,182 & 0 & $589,873.18$ & -0.27 \\
\hline & 37.50 & 1,387 & 17.34 & $638,098.40$ & 7.89 & & 37.50 & 1,181 & -0.08 & $589,095.36$ & -0.40 \\
\hline & 50 & 1,448 & 22.50 & $653,645.66$ & 10.51 & & 50 & 1,181 & -0.08 & $588,326.78$ & -0.53 \\
\hline \multirow{9}{*}{3} & -50 & 1,181 & 0 & $584,752.75$ & -1.13 & \multirow{9}{*}{6} & -50 & 2,366 & 100.17 & $898,725.28$ & 51.95 \\
\hline & -37.50 & 1,181 & 0 & $586,428.71$ & -0.85 & & -37.50 & 1,893 & 60.15 & $773,212.14$ & 30.73 \\
\hline & -25 & 1,182 & 0 & $588,104.68$ & -0.57 & & -25 & 1,577 & 33.42 & $690,981.22$ & 16.83 \\
\hline & -12.50 & 1,182 & 0 & $589,780.64$ & -0.28 & & -12.50 & 1,352 & 14.38 & $633,486.97$ & 7.11 \\
\hline & 0 & 1,182 & 0 & $591,456.61$ & 0 & & 0 & 1,182 & 0 & $591,456.61$ & 0 \\
\hline & 12.50 & 1,183 & 0 & $593,132.57$ & 0.28 & & 12.50 & 1,051 & -11.08 & $559,738.59$ & -5.36 \\
\hline & 25 & 1,183 & 0 & $594,808.54$ & 0.57 & & 25 & 945 & -20.05 & $535,241.98$ & -9.50 \\
\hline & 37.50 & 1,183 & 0 & $596,484.50$ & 0.85 & & 37.50 & 859 & -27.33 & $515,999.84$ & -12.76 \\
\hline & 50 & 1,184 & 0 & $598,160.47$ & 1.13 & & 50 & 787 & -33.42 & $500,700.86$ & -15.34 \\
\hline
\end{tabular}

per unit time. We recommend keeping it in the owned facility. However, we must remember that there is a capacity constrained. The management must manage it well to minimize the total cost per unit time. If the time decreases, company management must be careful. Since by lowering the value of the setup, changes in the capacity of the owned facility have a significant effect on the number of ordered items per cycle time and total cost per unit time. It means to increase the capacity of the owned facility can make the total cost per unit time lower. Company management should expand capacity at the owned facility, because it can save costs, in addition to capital investment. The longterm benefits of the company do not need to store items in the rented facility that charged by third parties. Last, changes in approximated weight of each grown item at the time of consumption has a significant effect on the number of ordered items per cycle time and total cost per unit time. It means by increasing the value of the approximated weight of each grown item at the time of consumption; it will reduce total cost per unit time, due to the high growth rate. If the growth rate is not too high, then the company management is more likely to set an approximated weight of each item at the time of consumption with a low value because it will reduce total cost per unit time. If the company sets with a high value, it will increase the total cost per unit time because there is a component, such as feeding cost (See Table 5).

Figure 2 presents the change of the number of ordered items per cycle time in six scenarios. Furthermore, Figure 3 presents the change of total cost per unit time in six scenarios.

\section{Conclusion}

This paper combines the concept of classic EOQ with some characteristics, they are, growing items, incremental discount quantity, capacitated storage facility, and limited budget. We develop a new mathematical model of EOQ. The proposed inventory model does not consider the multi-echelon and multi items concepts. The result of the comparative analysis shows that the proposed model is different than the reference model with respect to the number of ordered items per cycle time. In the proposed model that number is increased. If the feeding cost increases, then the total cost per unit time will be higher; otherwise, the total cost per unit time decreases. This conclusion is in line with the expected weight of items before being consumed, because if the item gets heavier, it will increase the feeding cost. Based on this finding, we suggest the management to be aware that by lowering the value of the setup cost. It will reduce the frequency for reordering yet will increase the order size, which is closely related to holding costs.

The changing value of holding costs in the rented facility will increase total cost per unit time because the holding cost in the rented facility is more expensive than in the owned facility. Therefore, company management should expand capacity at the owned facility, since it can save costs, in addition to capital investment. The long-term benefits of the company do not need to store items in rented facilities charged by third parties. 


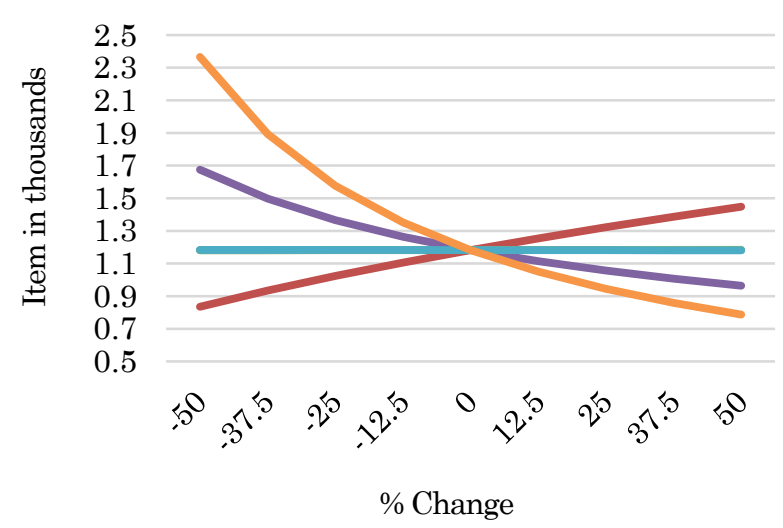

$\mathrm{c}=\mathrm{K} \longrightarrow \mathrm{ho} \longrightarrow \mathrm{hr}=\mathrm{m} 1$

Figure 2. Changes of $Y$ due to the change in $c, K, h_{o}, h_{r}, m$ and $w_{1}$

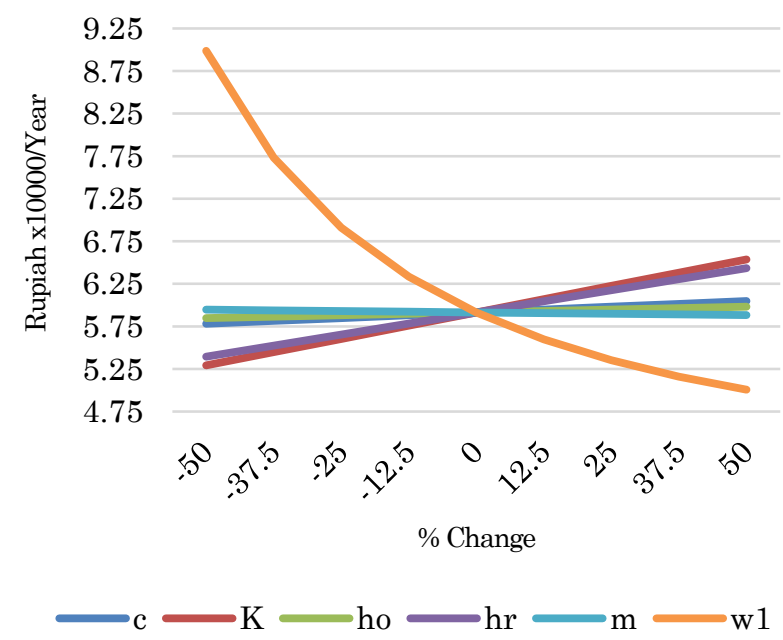

Figure 3. Changes of TCUdue to the change in $c, K, h_{o}, h_{r}, m$ and $w_{1}$

Furthermore, if the growth rate is not too high, it is more likely to set an approximated weight of each item at the time of consumption to a low value. This will reduce the total cost per unit time. Conversely, if it is set to a high value, the growth rate will increase the total cost per unit time. This happens because there is a cost component that affects the total cost per unit time, e. g. feeding cost.

\section{References}

1. Mishra, V.K. and Shanker, K., Optimal Ordering Quantities for Substitutable Items Under Joint Replenishment with Cost of Substitution, Journal of Industrial Engineering International, 13(3), 2017, pp. 77-104.

2. Rezaei, J., Economic Order Quantity for Growing Items, International Journal of Production Economics, 155, 2014, pp. 109-113.
3. Zhang, Y., Li, L., Tian, X., and Feng, C., Inventory Management Research for Growing Items with Carbon-constrained, Proceedings of the $35^{\text {th }}$ Chinese Control Conference, 2016, pp. 9588-9593.

4. Nobil, A.H., Sedigh, A.H.A., and CárdenasBarrón, L.E., A Generalized Economic Order Quantity Inventory Model with Shortage: Case Study of a Poultry Farmer, Arabian Journal for Science and Engineering, 44(3), 2019, pp. 26532663.

5. Sebatjane, M. and Adetunji O., Economic Order Quantity Model for Growing Items with Imperfect Quality, Operations Research Perspectives, 6, 2019.

6. Sebatjane, M. and Adetunji O., Economic Order Quantity Model for Growing Items with Incremental Quantity Discounts, Journal of Industrial Engineering International, 15(4), 2019, pp. 545556.

7. Sebatjane, M. and Adetunji O., Selected Deterministic Models for Lot Sizing of Growing Items Inventory, Theses, Department of Industrial and Systems Engineering, University of Pretoria, 2019.

8. Limansyah, T. and Lesmono D., Model Persediaan Multi Item dengan Mempertimbangkan Faktor Kedaluwarsa dan Faktor All Unit Discount, Jurnal Teknik Industri, 13(2), 2011, pp. 87-94.

9. Ghasmy Yaghin R., and Fatemi Ghomi, S.M.T., A Hybrid Credibility-Based Fuzzy Multiple Objective Optimisation to Differential Pricing and Inventory Policies with Arbitrage Consideration, International Journal of Systems Science, 46(14), 2014, pp. 2628-2639.

10. Holmbom M. and Segerstedt A., Economic Order Quantitates in Production: From Harris to Economic Lot Scheduling Problems, International Journal of Production Economics, 155, 2014, pp. 82-90.

11. Zhang Q., Tsao, Y.C. and Chen, T.H., Economic Order Quantity Under Advance Payment, Applied Mathematical Modelling, 38(24), 2014, pp. 5910-5921.

12. Taleizadeh, A.A., Stojkovska, I., and Pentico, D.W., An Economic Order Quantity Model with Partial Backordering and Incremental Discount, Computers and Industrial Engineering, 82, 2015, pp. 21-32.

13. Nafisah, L., Sally, W., and Puryani, P., Model Persediaan pada Produk yang Mendekati Masa Kedaluwarsa: Mempertimbangkan Diskon Penjualan dan Retur, Jurnal Teknik Industri, 18(1), 2016, 63-72.

14. Bohner, C. and Minner, S., Supplier Selection Under Failure Risk, Quantity and Business Volume Discount, Computers and Industrial Engineering, 104, 2017, pp. 145-155. 
15. Thamjidzad, S. and Mirmohammadi S.H., Optimal $(r, Q)$ Policy in a Stochastic Inventory System with Limited Resource Under Incremental Quantity Discount, Computers and Industrial Engineering, 103, 2017, pp. 59-69.

16. Mohammadivojdan, R. and Geunes, J., The Newsvendor Problem with Capacitated Suppliers and Quantity Discounts, European Journal of Operational Research, 271(1), 2018, pp. 109-119.

17. Khalilpourazari, S. and Pasandideh, S.H.R., Modelling and Optimization of Multi-Item MultiConstrainted EOQ Model for Growing Items, Knowledge-Based Systems, 164, 2019, pp. 150162.

18. Malekitabar M., Yaghoubi, S. and Golamian, M.R., A Novel Mathematical Inventory Model for Growing-Mortal Items (Case Study: Rainbow Trout), Applied Mathematical Modelling, 71, 2019, pp. 96-117.

19. Gharaei, A. and Almehdwe E., Economic Growing Quantity, International Journal of Production Economics, 223, 2020.

20. Oluleye, A.E., Oladokun V.O., and Anifanu S.O., Inventory Management of Resources with Discounts in a Manufacturing Industry (Case Study of Bottling Company), American Scientific
Research Journal for Engineering, Technology and Sciences, 64(1), 2020, pp. 119-132.

21. Raj, S.A. and Priskillal M., An Intuitionist Approach for an EOQ Model with Quantity Discounts, Studies in Indian Place Names, 40(60), 2020, pp. 662-671.

22. Rasay, H., and Golmohammadi, A.M., Modeling and Analyzing Incremental Quantity Discounts in Transportation Costs for a Joint Economic Lot Sizing Problem, Iranian Journal of Management Studies, 13(1), 2020, pp. 23-49.

23. Wangsa, I.D., and Wee H.M., Integrated Inventory System with Freight Costs and Two Types of Quantity Discounts, International Journal of Logistics Systems and Management, 35(1), 2020, pp. 119-147.

24. Liu, M. et al., Distributionally Robust Inventory Routing Problem to Maximize the Service Level Under Limited Budget, Transportation Research Part E, 126, 2019, pp. 190-211.

25. Bazaraa, M.S. and Shetty, C.M., Nonlinear Programming: Theory and Algorithms, Wiley, New York, 1979.

26. Hillier F.S. and Lieberman G.J., Introduction to Operations Research, Mc Graw Hill, New York, 2001. 